\title{
A join theoretical and experimental approach of electronic structure and photocatalytic properties of $\mathrm{MgWO}_{4}$ powders
}

Amanda F. Gouveia ${ }^{1,2^{*}}(\mathrm{PG})^{*}$, Victoria R. O. de Almeida ${ }^{1}(\mathrm{IC})$, Elson Longo $^{2}(\mathrm{PQ})$, Laécio S. Cavalcante ${ }^{1}$ (PQ), *amanda@liec.ufscar.br

${ }^{1}$ DQ-GERATEC, Universidade Estadual do Piauí, P.O. Box 381, 64002-150 Teresina, Piauí, Brazil

${ }^{2}$ CDMF, Universidade Federal de São Carlos, P.O. Box 676, 13565-905 São Carlos, São Paulo, Brazil

Keywords: electronic properties, photocatalytic degradation, theoretical calculation.

\section{Introduction}

Recently, the industrial organic dyes are large fluvial water contaminants that cause serious environmental problems [1]. A well-known industrial dye is the Rhodamine $\mathrm{B}(\mathrm{RhB})$, which is employed for the dyeing of cotton, weed, for example [2].

From a practical viewpoint, the photocatalytic (PC) properties with the action of a semiconductor catalyst is an alternative way for the removal of soluble toxic compounds, especially because of its significant advantages, such as: low cost, easy to handle, the reaction is promoted by means of visible or ultraviolet electromagnetic energy [3].

Therefore, the magnesium tungstate $\left(\mathrm{MgWO}_{4}\right)$ can be used for photocatalytic activity. We present first-principles calculations based on the density functional theory (DFT) to find a correlation between experimental results and electronic levels.

\section{Methodology}

$\mathrm{MgWO}_{4}$ powders were synthesized by the complex polymerization method modified [4] and was characterized by X-ray diffraction (XRD) patterns and Rietveld refinement. Their optical properties were investigated by UV-Vis spectroscopy. The PC properties for degradation of $\mathrm{RhB}$ were conducted under illumination UV-light up to 120 min. The theoretical calculation based on the DFT was performed with the CRYSTAL14 package [5].

\section{Results and Discussion}

This powder heat-treated at $900{ }^{\circ} \mathrm{C}$ for $2 \mathrm{~h}$, exhibits all XRD patterns ascribed to pure $\mathrm{MgWO}_{4}$ phase with monoclinic structure and also the structural refinement by means of Rietveld method. According to our theoretical calculations of the EBS, it was noticed that the $\mathrm{MgWO}_{4}$ is characterized by direct electronic transitions $\left(E_{\text {gap }}=4.49\right.$ $\mathrm{eV})$. This value is in concordance with the experimental $\mathrm{UV}-\mathrm{V}$ is spectrum value $\left(E_{\text {gap }}=\right.$ $4.33 \mathrm{eV}$ ), but it is a little higher because in the theoretical calculations the system is in the ideal structure without deep local defects. The projected DOS on the $\mathrm{O}$ atoms is principally determined in the VB with the $2 p$ orbitals while the $\mathrm{CB}$ is mainly determined by the $5 d$ orbitals from $\mathrm{W}$ atoms. In systems that present local defects, different $M-\mathrm{O}$ bonds in the $\left[M \mathrm{O}_{6}\right]$ clusters, where $M=\mathrm{Mg}$ and/or $\mathrm{W}$, it is to expected orbitals not degenerated. In this way, in the top of the VB there are contributions of $2 p_{x}$ and $2 p_{z}$ orbitals from $\mathrm{O}$ atoms whereas in the bottom of the $\mathrm{CB}$ a little contribution of $4 s$ orbitals from $\mathrm{Mg}$ atoms and $5 d_{z^{2}}, 5 d_{x z}$ and $5 d_{x^{2}-y^{2}}$ orbitals from $\mathrm{W}$ atoms.

\section{Conclusions}

In summary, we explained by means of distortions effects and proposed a PC mechanism based in a wide model related the presence of intermediate electronic levels between the VB and CB. 


\section{Acknowledgments}

The authors acknowledge the financial support of the Brazilian research financing institutions: CNPq (150949/2018-9; 312318/2017-0; 479644/2012-8, 304531/2013-8, 304531/2013-8), FAPESP (2013/07296-2), and CAPES.

\section{References}

[1] Assis FCC et al (2012), Desalination Water Treatment 39: 316.

[2] $\mathrm{Na} \mathrm{Y}$ et al (2005), Korean J. Chem. Engineering 22: 196.

[3] Kabra K et al (2004), Industrial Engineering Chemistry Research 43: 7683.

[4] Cavalcante LS et al (2008), Materials Science Engineering B: 15018.

[5] Dovesi R et al Theoretical Chemistry Group: University of Turin, Italy, 2014. 